\title{
The regulation of rabbit oviduct fluid formation
}

\author{
C. J. Dickens and H. J. Leese \\ Department of Biology, University of York, Heslington, York, YO1 5DD, UK
}

\begin{abstract}
The control of the formation of rabbit oviduct fluid and its relationship to the secretion of chloride ions has been studied using an in vitro vascularly perfused preparation. Fluid was produced at a rate of $43.41 \mu \mathrm{h} \mathrm{h}^{-1}$ in oviducts from rabbits in oestrus. The rate was increased by isoprenaline and tetraethylammonium, decreased by dibutyryl cAMP, dihydro4,4'diisothiocyanatostilbene-2,2'-disulfonic acid ( $\mathrm{H}_{2} \mathrm{DIDS}$ ), and propranolol, while amiloride had no effect. $\mathrm{H}_{2}$ DIDS induced a small decrease and isoprenaline a small increase in vascular to lumen $\mathrm{Cl}^{-}$flux but propranolol and dibutyryl cAMP had no effect. Oviducts from pseudopregnant animals treated with hCG three days before the experiment produced significantly less fluid than did those from rabbits in oestrus, but there was no difference in vascular to lumen $\mathrm{Cl}^{-}$flux. The concentration of $\mathrm{K}^{+}$in oviduct fluid formed in vitro was more than three times higher than in the vascular perfusate. The ability of adrenergic agents to influence the formation of rabbit oviduct fluid could have clinical implications in the prevention or treatment of female infertility due to blockage of the Fallopian tubes and might also be useful in enhancing the secretory activity of oviduct cells maintained in co-culture with early embryos.
\end{abstract}

\section{Introduction}

Although Fallopian tube (oviduct) fluid is the medium in which fertilization and early embryo development take place, little is known about the mechanisms underlying the secretion of specific constituents or the control of these processes (Leese, 1988; Leese and Dickens, 1992). Such information is important for three main reasons. First, blockage of Fallopian tubes is a major cause of infertility, accounting for $14 \%$ of cases in infertile couples in the UK (Hull et al., 1985). Tubal factors are also implicated in many cases of unexplained infertility. Information on the normal physiology of the tube is essential to understanding the onset of tubal pathology and could provide early markers of incipient damage. Second, there is a need to discover the nature of the advantage, if any, conferred by the Fallopian tube on embryo development, notably in co-culture experiments. This again requires knowledge of the physiology of tubal fluid formation. Moreover, the ability to enhance or inhibit total fluid output or the secretion of selected constituents could be used to augment any positive effect of the Fallopian tube on embryo development. Third, information on the permeability properties of the Fallopian tube wall could be valuable in the development and targeting of contraceptives designed against the gametes or early embryo.

The technique of vascular perfusion (Leese and Gray, 1985) and inhibitors of ion transport were used to show that chloride ions were involved in mediating fluid secretion in the rabbit oviduct (Gott et al., 1988). Brunton and Brinster (1971), using slices of rabbit oviduct mounted in an Ussing chamber, also reported a net serosal to mucosal $\mathrm{Cl}^{-}$flux. It is possible that changes in chloride ion flux are involved in the reduction in

Received 9 July 1993. volume of rabbit oviduct fluid which occurs 3 days after mating (Bishop, 1956; Gott et al., 1988; Dickens et al., 1992).

In other tissues, such as the small intestine (Cooke, 1987), trachea (Welsh, 1986; Leidke, 1989; Verkman et al., 1992) and sweat duct gland (Pedersen, 1990), fluid secretion is stimulated by adrenergic compounds via a change in cAMP concentration. Brunton (1972) found that agents such as cAMP, adrenaline and isoprenaline increased the short circuit current and potential difference across pieces of rabbit oviduct mounted in an Ussing chamber; the response to isoprenaline was blocked by propranolol, thus signifying beta adrenergic control of short circuit current.

To study fluid formation in as physiological a manner as possible, we used an in vitro vascular perfusion technique (Leese and Gray, 1985) in which the ovarian artery was cannulated and the vasculature perfused with an appropriate medium. At the same time, the lumen was cannulated enabling the formation of tubal fluid to be monitored continuously. The preparation is viable for at least $3 \mathrm{~h}$. We examined the effect of adrenergic agents, ion transport inhibitors and pseudopregnancy on fluid production and $\mathrm{Cl}^{-}$transport in the rabbit oviduct. A preliminary account of this work has been published (Dickens et al., 1992).

\section{Materials and Methods}

\section{Materials}

Rabbits were obtained from Harlan Olac Ltd, Bicester, Oxon and Froxfield Farms (UK) Ltd, Petersfield, Hampshire. Medium 199 was obtained from Flow Laboratories, High Wycombe, Bucks.; penicillin and streptomycin from Gibco Life 
Technologies Ltd, Paisley; BSA from ICN Immunobiologicals, High Wycombe, Bucks.; ${ }^{36} \mathrm{Cl}$ from Amersham, Aylesbury, Buckinghamshire; Ketaset and Domitor from Vet Drug Co., Dunnington, York; all other chemicals were from Sigma Chemical Co., Poole, Dorset.

\section{Vascular perfusion}

The vascular perfusion apparatus was described by Leese and Gray (1985). Virgin, female Dutch rabbits $(2.0-2.5 \mathrm{~kg})$ were anaesthetized with i.m. injections of $45 \mathrm{mg}$ Ketaset $\mathrm{kg}^{-1}$ and $0.5 \mathrm{mg}$ Domitor $\mathrm{kg}^{-1}$, maintained with $\mathrm{I}: 1$ Ketaset and distilled water via the marginal ear vein. When necessary, pseudopregnancy was induced by giving 50 iu hCG i.v. 3 days before the experiment.

A glass cannula was tied into the fimbriated end of the oviduct. The ovarian artery was dissected free of fat and loosely ligatured. The artery was clamped and an incision made above the clamp into which a fine glass cannula was inserted. The vasculature was perfused at a rate of $0.7 \mathrm{ml} \mathrm{min}^{-1}$ with Medium 199 supplemented with $0.4 \% \mathrm{BSA}, 4 \mathrm{U}$ heparin $\mathrm{ml}^{-1}$, $50 \mu \mathrm{g}$ penicillin ml ${ }^{-1}$, and $50 \mu \mathrm{g}$ streptomycin $\mathrm{ml}^{-1}$ gassed with $5 \% \mathrm{CO}_{2}$ in $\mathrm{O}_{2}$. The mean perfusion pressure was $83 \pm 2 \mathrm{mmHg}(n=61)$, and this remained constant throughout each experiment.

The uterine end of the oviduct was tied and a calibrated tube attached to a cannula secured in the fimbriated end. The oviduct was excised and placed in a water-jacketed dish in a $37^{\circ} \mathrm{C}$ constant temperature cabinet. There was usually a lag period of about $\mathrm{I} \mathrm{h}$ before fluid appeared in the lumen tube owing to the filling of the oviduct lumen. Oviduct fluid was then produced continuously and its progress along the tube could be monitored for up to $3 \mathrm{~h}$.

The effect on fluid formation of the addition of dibutyryl cAMP, dihydro4, $4^{\prime}$ diisothiocyanatostilbene-2, $2^{\prime}$-disulfonic acid $\left(\mathrm{H}_{2}\right.$ DIDS), tetraethylammonium, amiloride, isoprenaline and propranolol to the vascular medium was investigated.

In a separate series of experiments to study unidirectional ion transport from the vascular medium into the oviduct lumen, a second cannula was tied into the lumen of the uterine end of the oviduct. Krebs Ringer bicarbonate $\left(118 \mathrm{mmol} \mathrm{NaCl} 1^{-1}\right.$, $25 \mathrm{mmol} \mathrm{NaHCO}_{3} \mathrm{l}^{-1}, 4.74 \mathrm{mmol} \mathrm{KCl} \mathrm{l}^{-1}, 1.19 \mathrm{mmol}$ $\mathrm{MgSO}_{4} \mathrm{l}^{-1}, 1.17 \mathrm{mmol} \mathrm{KH}_{2} \mathrm{PO}_{4} \mathrm{l}^{-1}, 1.17 \mathrm{mmol} \mathrm{CaCl} \mathrm{I}^{-\mathrm{I}}$ gassed with $5 \% \mathrm{CO}_{2}$ in air) was perfused in a single pass through the lumen at a rate of $70 \mu \mathrm{min}^{-1}$. After a $10 \mathrm{~min}$ control period $7 \mathrm{kBq} \mathrm{ml}{ }^{-136} \mathrm{Cl}^{-}$was added to the vascular compartment and lumen wash-out samples were collected for intervals of $10 \mathrm{~min}$. A $90 \mathrm{~min}$ control period of $\mathrm{Cl}^{-}$ flux measurement was allowed before experimental agents (dibutyryl cAMP, $\mathrm{H}_{2}$ DIDS, isoprenaline and propranolol) were added to the vascular medium. Experiments were continued for a further $90 \mathrm{~min}$. Samples were added to $2 \mathrm{ml}$ 'Optiphase' and counted in a liquid scintillation counter.

\section{Analysis of oviduct fluid}

Oviduct fluid formed during the vascular perfusion experiments was collected and frozen at $-20^{\circ} \mathrm{C}$. The ionic composition was later analysed by electron probe $\mathrm{X}$-ray microanalysis. The method used was that of P. S. Hinde and
A. D. Tomos (unpublished) from the School of Biological Sciences, University College of N. Wales, Bangor. Triplicate samples were placed on a copper G100/200 mesh electron microscope grid under water-saturated paraffin oil using a constriction micropipette. An equal volume of RbFI was added to each sample. Standards for the ions to be measured were prepared in a similar manner. The completed grid was flash dried in water-saturated hexane followed by isopentane, air dried and stored over desiccant until analysis by EDAX (Energy Dispersive X-Ray Analysis).

The grids were mounted on carbon blocks and analysed using a Hitachi 5520 scanning electron microscope with a LINK QX2000 EDAX detector. The grids were oriented so that the electron beam and X-ray detector were at an angle of $45^{\circ}$. X-ray spectra were analysed using a beryllium window.

The osmotic pressure of oviduct fluid samples was also measured using a modified Clifton nanolitre osmometer.

\section{Statistical analysis}

The results are expressed as mean \pm SEM. The significance of differences between means was assessed by paired or Student's $t$ test as appropriate. Data for fluid formation and $\mathrm{Cl}^{-}$flux was measured from a series of readings once a steady state had been reached.

\section{Results}

\section{Rabbits in oestrus}

Fluid formation studies. The rate of fluid production in oviducts taken from rabbits in oestrus was $43.41 \pm 4.31 \mu \mathrm{h} \mathrm{h}^{-1}$ $(n=25)$. The addition of $1 \mathrm{mmol}$ dibutyryl cAMP $1^{-1}$ to the vascular perfusate immediately inhibited oviduct fluid formation from a mean rate of $47.7 \pm 7.08 \mu \mathrm{h} \mathrm{h}^{-1}$ to $6.55 \pm$ $4.04 \mu \mathrm{h} \mathrm{h}^{-1}$ ( $n=4, \mathrm{P}=0.015$; see Fig. 1). The $\mathrm{Cl}^{-}-\mathrm{HCO}^{-}$ exchange inhibitor $\mathrm{H}_{2}$ DIDS $\left(1 \mathrm{mmol} \mathrm{l}^{-1}\right)$ reduced oviduct fluid formation by $77 \%$, from a mean rate of $45.54 \pm 6.78 \mu \mathrm{l} \mathrm{h}^{-1}$ to $10.26 \pm 2.80 \mu \mathrm{l} \mathrm{h}^{-1}(n=6, P=0.004)$.

Addition of $25 \mathrm{mmol}$ tetraethylammonium $\mathrm{l}^{-1}$ (TEA), a K ${ }^{+}$ channel blocker, to the vascular medium stimulated fluid formation from $46.04 \pm 13.03$ to $129.01 \pm 34.73 \mu \mathrm{l} \mathrm{h}^{-1}(n=6$, $P=0.044)$, whereas $1 \mathrm{mmol}$ amiloride $\mathrm{I}^{-1}$, a Na${ }^{+}-\mathrm{H}^{+}$ exchange inhibitor, had no effect on fluid transport (control rate of $36.78 \pm 11.04 \mu \mathrm{h} \mathrm{h}^{-1}$ compared with $35.76 \pm 9.06 \mu \mathrm{l} \mathrm{h}^{-1}$, $(n=4))$. These results are summarized (Fig. 1).

The effect of adrenergic agonists was examined. Adrenaline was an inappropriate agent to use as it raised arterial pressure owing to the stimulation of alpha receptors in the oviduct (Black, 1974). When $100 \mu \mathrm{mol}$ isoprenaline $\mathrm{l}^{-1}$, a beta adrenergic stimulator, was added to the vascular medium, a large, prolonged increase (for up to $1 \mathrm{~h}$ ) in oviduct fluid formation, from a control rate of $49.56 \pm 9.42$ to $120.00 \pm 37.68 \mu \mathrm{l} \mathrm{h}^{-1}$, a rise of $142 \%(n=9, P=0.063)$ was induced. Similar results were obtained with $1 \mathrm{mmol}$ isoprenaline $\mathrm{I}^{-1}(n=3)$. After the addition of the beta adrenergic antagonist, propranolol (100 $\mu \mathrm{mol} \mathrm{I}^{-1}$ ), the rate fell to $27.90 \pm 10.86 \mu \mathrm{h} \mathrm{h}^{-1}$, a fall to $44 \%$ of the initial control value $(n=5, P=0.003)$ (Fig. 2). 


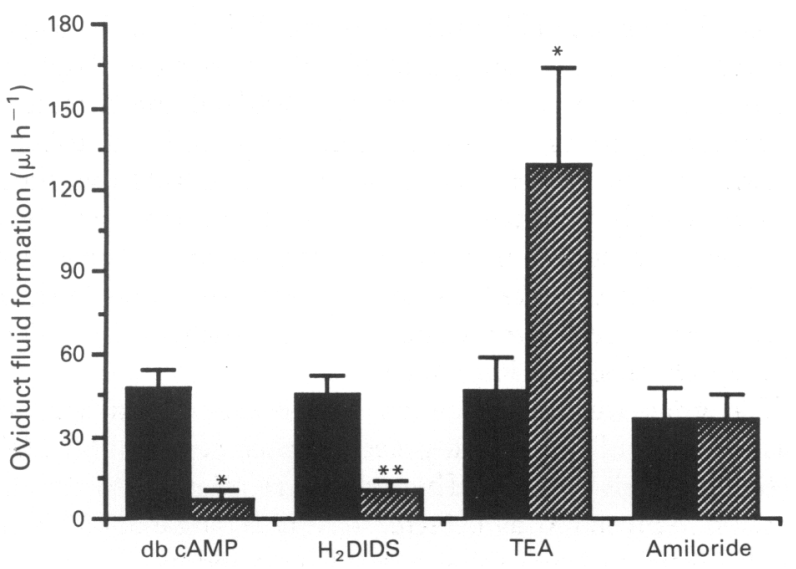

Fig. 1. The rate of fluid formation $\left(\mu \mathrm{l} \mathrm{h}^{-1}\right)$ in oviducts taken from rabbits in oestrus. Results are paired data. $(\boldsymbol{\square})$ : the control period during the first part of the experiment; (匀): the rate of fluid formation under experimental conditions. db cAMP: $1 \mathrm{mmol}$ dibutyryl cAMP $\mathrm{l}^{-1}(n=4) ; \mathrm{H}_{2}$ DIDS: $1 \mathrm{mmol}$ dihydro4,4'-diisothiocyanatostilbene2,2'-disulfonic acid $1^{-1}(n=6)$; TEA: $25 \mathrm{mmol}$ tetraethyl ammonium $1^{-1}(n=6)$ and $1 \mathrm{mmol}$ amiloride $1^{-1}(n=4)$ added to the vascular medium. Values are means \pm SEM. Significantly different from control $\left({ }^{*} P<0.05,{ }^{* *} P<0.01\right)$.

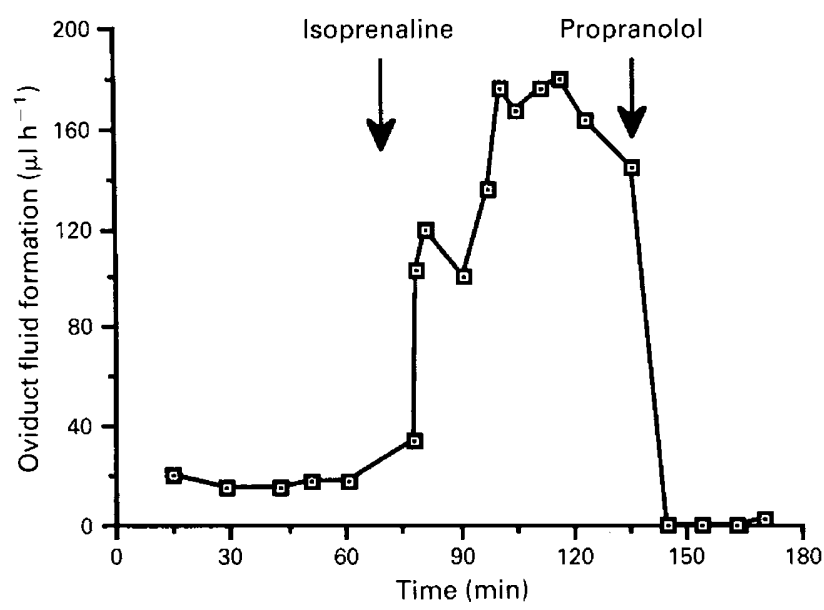

Fig. 2. Rate of formation of rabbit oviduct fluid $\left(\mu l \mathrm{~h}^{-1}\right)$ when, after a control period of $70 \mathrm{~min}, 100 \mu \mathrm{mol}$ isoprenaline $\mathrm{l}^{-1}$ (final concentration) was added to the vascular medium. After a further $65 \mathrm{~min}$, $100 \mu \mathrm{mol}$ propranolol $\mathrm{i}^{-1}$ (final concentration) was also added to the vascular medium.

The different effects exerted by dibutyryl cAMP and isoprenaline on fluid transport were unexpected. Perfusions were therefore carried out in which isoprenaline was added to the vascular medium followed later by dibutyryl cAMP in the same experiment. The control rate of fluid formation was $35.64 \pm 8.40 \mu \mathrm{h} \mathrm{h}^{-1}(n=5)$. After the addition of isoprenaline it increased to $63.90 \pm 20.82 \mu \mathrm{h} \mathrm{h}^{-1}$ before falling to a mean of $23.70 \pm 9.66 \mu \mathrm{l} \mathrm{h}^{-1}$ with the addition of dibutyryl cAMP (that is, below the control rate).

Ion transport studies. The mean rate of $\mathrm{Cl}^{-}$transport from the vascular compartment into the lumen was $15.7 \pm 1.85 \mu \mathrm{mol}$

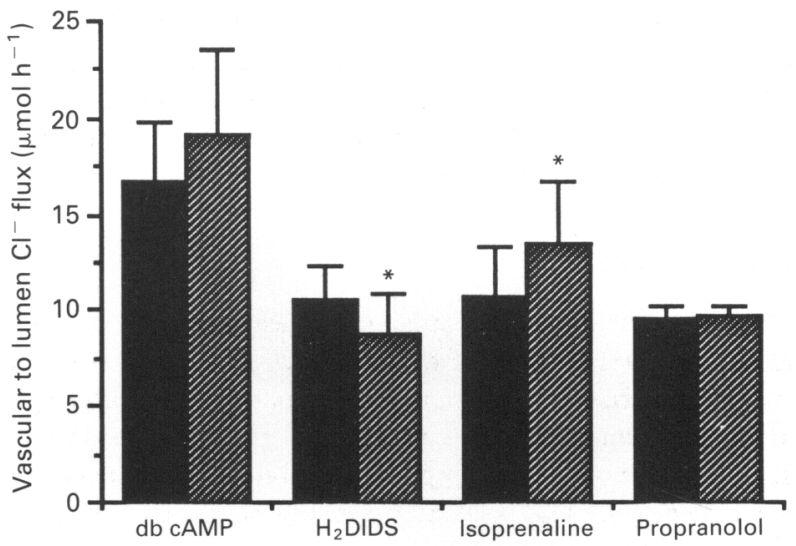

Fig. 3. Vascular to lumen $\mathrm{Cl}^{-}$flux $\left(\mu \mathrm{mol} \mathrm{h} \mathrm{h}^{-1}\right)$ across rabbit oviducts. db cAMP: 1 mmol dibutyryl cAMP $1^{-1}(n=5) ; \mathrm{H}_{2}$ DIDS: $1 \mathrm{mmol}$ dihydro $4,4^{\prime}$-diisothiocyanatostilbene-2, $2^{\prime}$-disulfonic acid $\mathrm{l}^{-1}(n=5)$, $100 \mu \mathrm{mol}$ isoprenaline $\mathrm{I}^{-1}(n=7)$ and $100 \mu \mathrm{mol}$ propranolol $1^{-1}$ $(n=4)$ added to the vascular medium of the preparation after a steady control flux had been established. ( $\square$ ) Control flux during the first part of the experiment; ( are means \pm SEM. ${ }^{*}$ Significantly different from control $(P<0.05)$.

$\mathrm{h}^{-1}$ for rabbits in oestrus $(n=26)$. Addition of $1 \mathrm{mmol}$ dibutyryl cAMP $1^{-1}$ to the vascular compartment had no significant effect on $\mathrm{Cl}^{-}$transport into the oviduct lumen, with a rate of $16.67 \pm 3.06 \mu \mathrm{mol} \mathrm{h}^{-1}$ before and $19.21 \pm 4.28 \mu \mathrm{mol}$ $\mathrm{h}^{-1}$ after addition of cAMP ( $n=5, P=0.4$, see Fig. 3). Chloride ion transport was also monitored after the addition of $\mathrm{H}_{2}$ DIDS to the vascular medium. Over a $30 \mathrm{~min}$ period, $1 \mathrm{~h}$ after the addition of $\mathrm{Immol} \mathrm{H}_{2}$ DIDS $\mathrm{l}^{-1}$, there was a small but significant fall in $\mathrm{Cl}^{-}$flux compared with control values before the addition of $\mathrm{H}_{2}$ DIDS, from $10.53 \pm 1.78 \mu \mathrm{mol} \mathrm{h}^{-1}$ to $8.81 \pm 2.09 \mu \mathrm{mol} \mathrm{h}^{-1}(n=5, P=0.028)$.

Similar experiments were carried out in which $100 \mu \mathrm{mol}$ isoprenaline $\mathrm{l}^{-1}$ was added to the vascular compartment after an initial $90 \mathrm{~min}$ control period. During the first $30 \mathrm{~min}$ after addition of isoprenaline, there was a significant increase in $\mathrm{Cl}^{-}$ flux, from $10.71 \pm 2.54$ to $13.44 \pm 3.36 \mu \mathrm{mol} \mathrm{h}^{-1} \quad(n=7$, $P=0.025$ ). In a separate series of experiments, the addition of $100 \mu \mathrm{mol}$ propranolol $\mathrm{l}^{-1}$ to the vascular compartment had no effect on $\mathrm{Cl}^{-}$transport ( $\left.n=4\right)$ (Fig. 3).

\section{hCG-treated rabbits}

The rate of fluid formation was monitored in oviducts taken from day 3 pseudopregnant rabbits. In five experiments, the mean rate of fluid formation was $21.42 \pm 3.19 \mu \mathrm{h} \mathrm{h}^{-1}$, significantly lower than the rate of $43.41 \pm 7.08 \mu \mathrm{l} \mathrm{h}^{-1}(n=25)$ obtained for oviducts obtained from rabbits in oestrus $(P=0.0001 ;$ Fig. 4a). Chloride ion transport from the vascular medium to the oviduct lumen in hCG treated animals (13.56 $\left.\pm 3.74 \mu \mathrm{mol} \mathrm{h}^{-1}, n=4\right)$ was not significantly different from that found in animals in oestrus ( $\left.15.71 \pm 1.85 \mu \mathrm{mol} \mathrm{h}^{-1}\right)$ $(n=26$, Fig. 4 b) .

\section{Composition of oviduct fluid}

The concentrations of $\mathrm{Na}^{+}, \mathrm{K}^{+}$and $\mathrm{Cl}^{-}$were analysed in fluid collected during the control period of perfusion of 

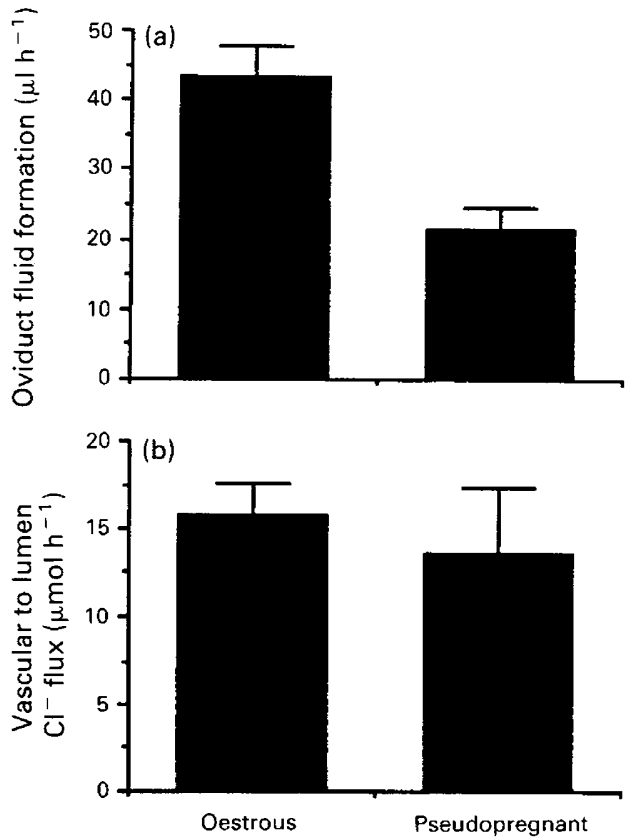

Fig. 4. (a) Fluid production $\left(\mu l h^{-1}\right)$ in oviducts from rabbits in oestrus (oestrous; $n=25$ ) and from rabbits treated 3 days previously with hCG (pseudopregnant; $n=5$ ). (b) Vascular to lumen $\mathrm{Cl}^{-}$transport $\left(\mu \mathrm{mol} \mathrm{h}{ }^{-1}\right)$ in oestrous $(n=26)$ and pseudopregnant rabbits $(n=4)$. Bars represent means \pm SEM.

oviducts from rabbits in oestrus (Table 1 ). The concentration of $\mathrm{K}^{+}$in oviduct fluid was more than three times higher than in the vascular perfusate, whereas $\mathrm{Na}^{+}$and $\mathrm{Cl}^{-}$concentrations were similar to those in the perfusate. The osmolarity of fluid in the oviduct was similar to that of Medium 199 and of rabbit plasma.

\section{Discussion}

The technique of vascular perfusion enables the formation of rabbit oviduct fluid to be monitored continuously for at least $3 \mathrm{~h}$. Once a steady rate is established, potential modulators may be added to the vascular perfusate and their effect on fluid production compared with the initial control rate. By perfusing the lumen, the unidirectional flux of ions from the vascular compartment may also be studied. Attempts were made to measure the absorptive $\mathrm{Cl}^{-}$flux, that is, in the lumen to vascular direction, but the results proved unreliable.

We have shown that the rate of formation of oviduct fluid is inhibited by $\mathrm{H}_{2}$ DIDS, and stimulated by TEA, with amiloride having no effect. Although $\mathrm{H}_{2}$ DIDS is not solely specific for the inhibition of $\mathrm{Cl}^{-}-\mathrm{HCO}_{3}{ }^{-}$exchange, the data did suggest a role for chloride ions in the production of oviduct fluid. However, there was little correlation between the effect of the various agents on fluid formation and on vascular to lumen chloride flux, indicating that other ions or metabolites must be involved in fluid secretion. A likely candidate is potassium, the concentration of which is about three times greater in oviduct fluid than in plasma (this study and Brackett and Mastroianni (1974)). This contention is supported by the effect of TEA on fluid formation. TEA is considered to block the $\mathrm{K}^{+}$channels involved in recycling $\mathrm{K}^{+}$across the basolateral membrane, concomitant with the action of the $\mathrm{Na}^{+}-\mathrm{K}^{+}$ATPase. This could lead to a rise in intracellular $\mathrm{K}^{+}$and force its exit into the lumen via apical $\mathrm{K}^{+}$channels (James and Okada, 1990), thereby drawing water into the lumen and leading to the observed increase in oviduct fluid production.

The concentration of sodium ions is also slightly higher in oviduct fluid than in plasma (this study), although the lack of effect of amiloride would seem to preclude its involvement in fluid production. The observation that the osmolality of the fluid formed was similar to that of the vascular perfusate indicates that water transport is isotonic in this tissue.

A reduction in the rate of fluid production by pseudopregnant animals has been reported by Bishop (1956), Gott et al. (1988) and Leese (1988), and may be associated with the passage of the embryo from the oviduct into the uterus. The fall in fluid production was not associated with a change in $\mathrm{Cl}^{-}$ transport, and other mechanisms are therefore likely to be involved as discussed above. For example, there is some evidence for a change in the concentrations of $\mathrm{H}^{+}$(Mass et al., 1979), $\mathrm{Na}^{+}$and $\mathrm{Ca}^{2+}$ (Holmdahl and Mastroianni, 1965) in rabbit oviduct fluid collected after ovulation.

The results reported here represent the first direct evidence for the regulation of oviduct fluid formation by adrenergic agents. However, such agents could act at a variety of sites as is the case in the anatomically similar small intestine (Cooke, 1987). For example, alpha- and beta-receptors have been found in the musculature and vasculature of rabbit oviducts (Black, 1974) and in oviduct epithelial cells in rats (Tolszczuk and Pelletier, 1988) and rabbits (Dickens et al., 1993). The receptors in the musculature are thought to be under ovarian steroid

Table 1. Ion concentrations and osmolality of oviductal fluid from rabbits in oestrus, Medium 199 and doe plasma

\begin{tabular}{|c|c|c|c|c|}
\hline Source & $\mathrm{Na}^{+}\left(\mathrm{mmol} \mathrm{l}{ }^{-1}\right)$ & $\mathrm{Cl}^{-}\left(\mathrm{mmol} \mathrm{l}{ }^{-1}\right)$ & $\mathrm{K}^{+}\left(\mathrm{mmol} \mathrm{l} \mathrm{l}^{-1}\right)$ & Osmolality (mosmol l $\left.{ }^{-1}\right)$ \\
\hline Rabbit oviductal fluid ${ }^{a}$ & $183 \pm 7$ & $132 \pm 8$ & $18 \pm 2$ & $307 \pm 12$ \\
\hline Medium $199^{b}$ & 170 & 127 & 5.4 & 306 \\
\hline Doe plasma ${ }^{c}$ & $142 \pm 1$ & $104 \pm 3$ & $3.7 \pm 0.2$ & $293 \pm 2$ \\
\hline
\end{tabular}

\footnotetext{
${ }^{a}$ Mean \pm SEM from samples of fluid from five experiments.

${ }^{b}$ Calculated from composition data supplied by the manufacturer.

'Data from Brackett and Mastroianni (1974).
} 
control; alpha-receptors are influenced by oestrogen and betareceptors by progesterone (Black, 1974). However, with regard to their effect on fluid transport, we consider that the epithelial cells lining the oviduct lumen are the most likely targets for adrenergic agents as these agents have a dramatic effect on primary cultures of polarized monolayers of rabbit oviduct epithelial cells (Dickens et al., 1993).

Our results lead to a paradox in that it is well established that beta adrenergic agonists, such as isoprenaline exert their effect via an increase in the intracellular cAMP concentration (Brunton, 1972; Pedersen, 1990; Verkman et al., 1992), whereas our data clearly show that CAMP and isoprenaline have opposite effects on the rate of oviduct fluid formation. To our knowledge this apparent anomaly has not been reported in other tissues. There are two possible explanations. First, cAMP may not be the second messenger for isoprenaline in the rabbit oviduct. Second, isoprenaline added exogenously may give rise to a different response in terms of intracellular cAMP concentration to that induced by external cAMP, which could be acting at other levels in the tissue, such as the vasculature, the stromal cells or the musculature, as discussed above.

Adrenergic agents, of which a great many have been tested clinically, might, by their action on oviduct fluid formation be useful in treating or preventing blockage of Fallopian tubes and also in enhancing, or inhibiting, the secretory activity of oviduct cells maintained with early embryos in co-culture.

The authors wish to thank D. R. Brison (University of York) and colleagues at the University College of N. Wales, Bangor (P. S. Hinde and $\mathrm{A}$. D. Tomos) for the electron probe $\mathrm{X}$-ray microanalysis. This work was supported by the Medical Research Council.

\section{References}

Bishop DW (1956) Active secretion in the rabbit oviduct American Joumal of Physiology 187 347-352

Black DL (1974) Neural control of oviduct musculature. In The Oviduct and its Functions pp 65-118 Eds AD Johnson and CW Foley. Academic Press, New York and London
Brackett BG and Mastroianni L, Jr (1974) Composition of oviductal fluid. In The Oviduct and its Functions pp 133-159 Eds AD Johnson and CW Foley. Academic Press, New York and London

Brunton W (1972) Beta-adrenergic stimulation of transmembrane potential and short circuit current of isolated rabbit oviduct Nature New Biology 236 12-14

Brunton WJ and Brinster RL (1971) Active chloride transport in the isolated rabbit oviduct American Journal of Physiology $221658-661$

Cooke HJ (1987) Neural and humoral regulation of small intestinal electrolyte transport. In Physiology of the Gastrointestinal Tract pp 1307-1350 Ed. LR Johnson. Raven Press, New York

Dickens CJ, Brison DR and Leese HJ (1992) The control of oviduct fluid formation Journal of Reproduction and Fertility Abstract Series 10 Abstract 78

Dickens CJ, Southgate J and Leese HJ (1993) Use of primary cultures of rabbit oviduct epithelial cells to study the ionic basis of tubal fluid formation Journal of Reproduction and Fertility 98 603-610

Gott AL, Gray SM, James AF and Leese HJ (1988) The mechanism and control of rabbit oviduct fluid formation Biology of Reproduction 39 758-763

Holmdahl TH and Mastroianni L (1965) Continuous collection of rabbit oviduct secretions at low temperature Fertility and Sterility 16 387-395

Hull MGR, Glazener CMA, Kelly NJ, Conway DI, Foster PA, Hinton RA, Coulson C, Lambert PA, Watt EM and Desai KM (1985) Population study of causes, treatment, and outcome of infertility British Medical Journal 291 1693-1697

James AF and Okada Y (1990) Single channel recordings from rabbit oviduct epithelial cells Japanese Joumal of Physiology $40 S$

Leese $\mathrm{HJ}$ (1988) The formation and function of oviduct fluid Journal of Reproduction and Fertility 82 843-856

Leese HJ and Dickens CJ (1992) Tubal Physiology and Function. In Infertility, pp 157-168 Eds AA Templeton and JO Drife. Springer-Verlag, London

Leese HJ and Gray SM (1985) Vascular perfusion: a novel means of studying oviduct function American Journal of Physiology 248 E624-E632

Leidke CM (1989) Regulation of chloride transport in epithelia Annual Review of Physiology 51 143-160

Mass DHA, Storey BT and Mastroianni L, Jr (1979) Hydrogen ion and carbon dioxide content of the oviductal fluid of the rhesus monkey (Macaca mulatta) Fertility and Sterility 28 981-985

Pedersen PS (1990) Chloride permeability regulation via a cyclic AMP pathway in cultured human sweat duct cells Journal of Physiology 421 379-397

Tolszczuk M and Pelletier G (1988) Autoradiographic localization of betaadrenergic receptors in rat oviduct Molecular and Cellular Endocrinology 60 95-99

Verkman AS, Chao AC and Hartman T (1992) Hormonal regulation of Cl transport in polar airway epithelia measured by a fluorescent indicator American Journal of Physiology 262 C23-C31

Welsh MJ (1986) Adrenergic regulation of ion transport by primary cultures of canine tracheal epithelium: cellular electrophysiology Joumal of Membrane Biology 91 121-128 